\title{
DINAMIKA INOVASI PADA KLUSTER INDUSTRI PARIWISATA BALI MELALUI KERJASAMA PEMERINTAH-UNIVERSITAS-INDUSTRI
}

\author{
Lalu M. Furkan ${ }^{1}$, Handry Sudiartha $\mathrm{A}^{2}$, Agusdin ${ }^{3}$ \\ ${ }^{I}$ Fakultas Ekonomi dan Bisnis Universitas Mataram, alu.furkan@gmail.com \\ ${ }^{2}$ Fakultas Ekonomi dan Bisnis Universitas Mataram, \\ ${ }^{3}$ Fakultas Ekonomi dan Bisnis Universitas Mataram,dragusdin@gmail.com
}

\begin{abstract}
ABSTRAK
Pariwisata menjadi topik yang diagendakan di Indonesia seperti di Bali dimana pembangunan ekonomi yang didukung oleh master rencana untuk ekspansi dan percepatan pembangunan ekonomi indonesia tahun 2011-2025. Hal ini disebutkan dalam koridor pembangunan nomor 5 disebut koridor pariwisata dan sumber pangan nasional di mana bali termasuk ke kawasan wisata pembangunan. Dalam mengembangkan pariwisata berkelanjutan di Bali diperlukan strategi pembangunan ekonomi, inovasi bermain peran penting. Oleh karena itu, tujuan penelitian ini adalah untuk mengidentifikasi inovasi di dalam industri kerajinan cluster indonesia sebagai salah satu bagian industri pariwisata. Kerangka survei perusahaan untuk diidentifikasi adalah perusahaan yang melakukan kegiatan inovasi di dalam cluster. Survei 33 pemilik perusahan dan eksekutif dengan menggunakan kuesioner dan teknik in-depth interview digunakan untuk mengeksplorasi tingkat kegiatan inovasi. Hasil penelitian mengidentifikasi banyak jenis inovasi dilakukan. Inovasi telah banyak didukung oleh banyak lembaga dalam industri cluster kerajinan di Bali. Jejaring yang kompleks telah menyiapkan lebih banyak pengetahuan dan teknologi bagi cluster industri kerajinan di Bali. Oleh karena itu, temuan dalam penelitian ini adalah adanya hubungan diantara lembaga maupun institusi kerajinan di Bali.
\end{abstract}

Kata Kunci: Cluster, Inovasi, UMKM, Industri Kreatif, Industri Kerajinan

\section{ABSTRACT}

Tourism has became topical agenda in Indonesia as well as in Bali Economic development which is supported by the Master Plan for Expansion and Acceleration of the Indonesia Economic Development 2011-2025. It is mentioned in corridor of development number 5 called Tourism \& Food National Support Corridor where Bali is included to the tourism area development. In order to develop sustainable tourism for the Bali economic development strategy, innovation play important role. Therefore, aim of this research is to identify innovation activities in the Indonesian craft industrial cluster as one of the broad tourism industry players. A framework of company survey was taken to identify their innovation activities in the cluster. Survey of 33 company owners and executives using quessionaires and in-depth interview technique explores their level of innovation activities. Thus research result found many types of innovation presented on the paper. Those types of innovation has been supported by many institutions in the Balinese craft industrial cluster. The more complex network has been set up the more knowledge and technology flows into the Balinese craft industrial cluster. Therefore, new types of inter-relationship among institutions in the Balinese craft industry is called innovation in the research.

Keywords: Cluster, Innovation, SMEs, Creative industry, Handicraft industry 


\section{PENDAHULUAN}

\section{Latar Belakang}

Industri pariwisata merupakan salah satu industry terbesar di dunia. Hal ini dapat dilihat dari data statistic yang menunjukkan jumlah kunjungan wisatawan asing yang melakukan kunjungan internasional (international visitor) telah meningkat signifikandari tahun ke tahun. Pertumbuhan jumlah pengunjung international di seluruh dunia meningkat $4 \%$ hingga mencapai 1,035 miliar international visitors pada tahun 2012. Berikut adalah data dan ramalan jumlah kunjungan international visitors diseluruh dunia (UNWTO,2012)

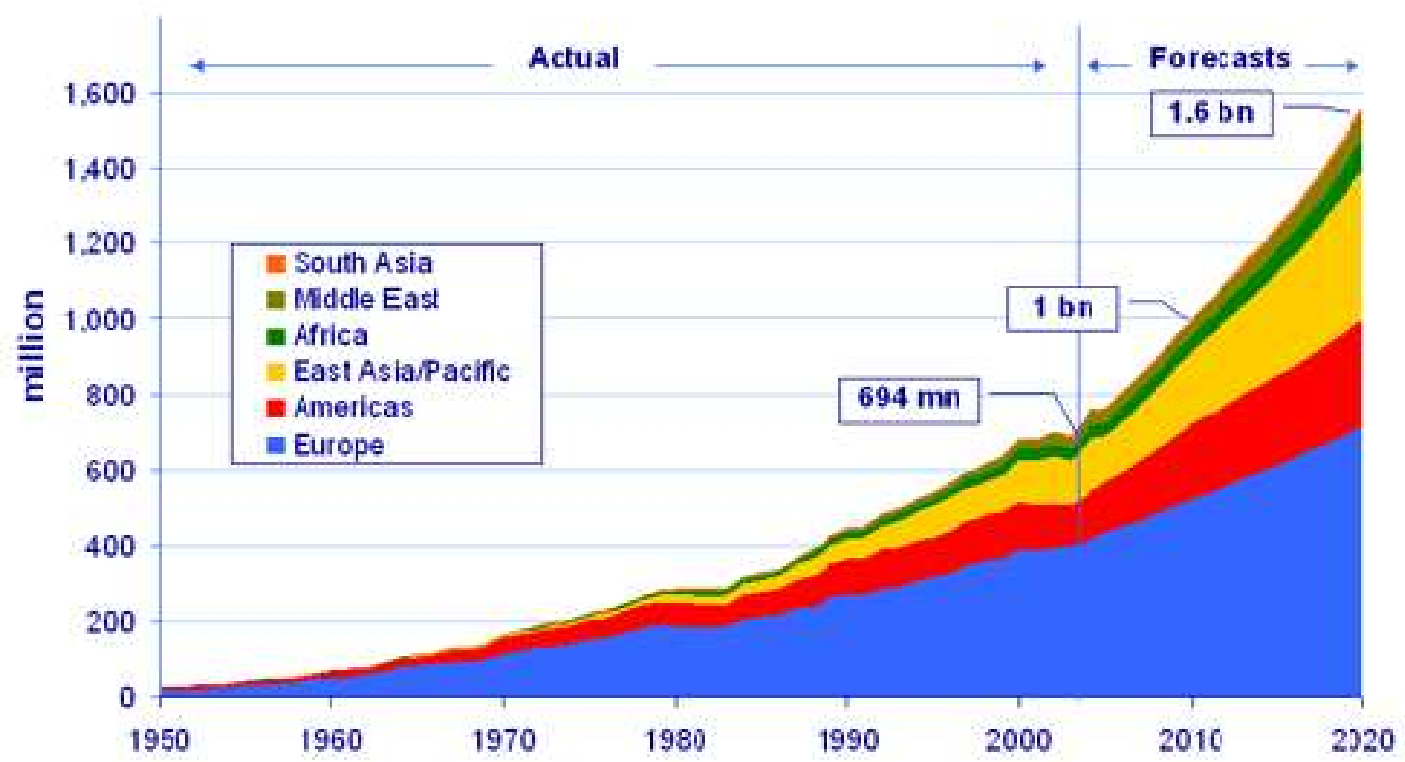

Gambar 1. Data jumlah kunjungan international didunia

Gambar 1 menunjukkan data actual dan ramalan jumlah kunjungan pada 6 regional area: Asia Selatan, Timur Tengah, Afrika, Asia Timur/ Pacific, Amerika dan Eropa. Eropa merupakan wilayah yang paling banyak dikunjungi international visitors. Jika dilihat dari sudut pandang pertumbuhan jumlah kunjungan international pada berbagai wilayah diatas, maka kedatangan international visitors di Negara emerging economy $(4,1 \%)$ lebih tinggi dari Negara maju $(3,6 \%)$. Jika dilihat dari aspek regional, kedatangan international visitors di Asia pasifik (7\%) merupakan pertumbuhan terbaik dibandingkan wilayah lain. Lebih jauh jika dilihat dari sub-region Asia Tenggara dan Afrika Utara (9\%) dan diikuti oleh Eropa Tengah dan Timur (8\%). Keunikan Asia Tenggara akan terus menjadi contributor yang signifikan bagi perkembangan jumlah international visitors di seluruh dunia. Pertmbuhan jumlah kunjungan international visitors di Asia tenggara berdampak pada jumlah kunjungan di Indonesia dan berdampak signifikan pada industry terkait bidang pariwisata Indonesia.

Strategi pembangunan pemerintah republic Indonesia melalui Master Plan Percepatan Pembangunan Republik Indonesia memprioritaskan koridor 5 sebagai koridor pengembangan pariwisata yang terdiri dari Provinsi Bali, NTB, NTT. Pertumbuhan jumlah kunjungan wisatawan international dan domestic memiliki dampak multiplier terhadap berbagai sector industry pariwisata termasuk sector industry kreatif yang merupakan industry pendukung pariwisata nasional yang cukup prospektif. 
Kajian ini akan memfokuskan diri pada dinamika inovasi industry kreatif sebagai industry pendukung pariwisata di Pulau Bali. Department for Culture. Media and Sport (DCMS,1998) mendefinisikan industry kreatif sebagai aktifitas yang memiliki originalitas dalam kreatifitas individu. Hal ini meliputi: pertunjukan seni, periklanan, arsitektur, barang seni dan antic, design, designer fashion, film and video, interactive software (computer games), music, penerbitan, software dan jasa computer, television dan radio, dan industry kerajinan. Meskipun terdapat peningkatan jumlah kajian dalam industry kreatif tetapi masih menimbulkan banyak pertanyaan. Sebagai contoh, apakah industry kreatif mampu mengembangkan produk budaya yang original dan unik secara berkesinambungan?(German Comission for UNESCO, 2007). Hingga saat ini, hanya sedikit kajian tentang inovasi dalam industry kreatif (Miles \& Green, 2008). Kajian tentang konten inovasi jarang di artikulasikan dalam kajian inovasi. Hal ini lebih banyak ditemukan dalam kajian budaya, dan bahkan masih belum di potret dalam perspektif inovasi (Wright, Boria, \& Breidenbach, 2002; Zackariasson, Walfisz, dan Wilson, 2006) Lebih jauh lagi, banyak kajian menekankan pentingnya melakukan kajian inovasi dalam industry kreatif dalam kaitannya dengan karakteristik sector industry kreatif tersebut (Handke, 2008).

Tujuan riset ini adalah mengidentifikasi dinamika inovasi yang terjadi dalam industry kreatif khususnya industry kerajinan di Pulau Bali.Untuk mencapai tujuan dalam penelitian ini, pertama, peneliti melakukan survey literature. Tujuan survey literature adalah untuk memahami teori teori inovasi dan para actor yang terlibat dalam kluster. Penelitian ini memberikan definisi inovasi berdasarkan teori teori yang ada dan lebih jauh mengeksplorasi phenomena praktik inovasi yang telah di teliti. Hal ini mampu menerangkan tentang sumber inovasi dan actor actor yang berperan didalam kluster melalui networking yang tersedia. Setelah itu konsep kluster, inovasi, network diperkenalkan untuk membantu memahami inovasi yang terjadi dalam sebuah kluster. Kedua, setelah menyusun landasan teori, sample survey dilakukan dengan mengunjungi 33 perusahaan dalam kluster. Peneliti menanyakan pertanyaan terkait inovasi yang telah tersusun dalam angket pertanyaan kepada penanggung jawab perusahaan.Teknik wawancara dengan panduan instrument quessionaires diisi oleh peneliti langsung untuk menghindari kesalah pahaman dalam memahami konteks pertanyaan.Wawancara mendalam juga dilakukan agar mendapatkan pemahaman yang lebih baik tentang inovasi yang terjadi dalam kluster.Ketiga, tujuan sample survey yang dilakukan adalah untuk mengumpulkan data informasi tentang praktek inovasi dalam kluster dan menjelaskan network yang terjadi dalam kluster.

Quessionaires dalam smple survey ini terdiri dari 5 bagian dan dibagian depan quessionaires terdapat tujuan dari riset ini. Pertama, informasi bisnis secara umum terdiri dari cakupan luas area pasar, perubahan signifikan yang terjadi dalam bisnis dan pentingnya tujuan perusahaan yang dimaksud. Kedua, pertanyaan memfokuskan pada aktivitas inovasi dalam kluster.Ketiga, pertanyaan memfokuskan pada actor actor yang terlibat dalam kluster.Keempat, pertanyaan memfokuskan pada jenis perlindungan inovasi yang dimiliki dalam kluster.

\section{Tinjauan Pustaka}

\section{Pendekatan Cluster}

Terdapat perbedaan pandangan tentang konsep kluster antar para ahli. Para ahli atau peneliti kluster memiliki definisi yang berbeda tentang kluster karena hingga detik ini tidak ada kesepakatan tentang definisi atau kerangka konseptual kluster. Hal ini diperkuat oleh Feser (1998) yang menekankan bahwa tidak ada teori tentang kluster 
yang telah disepakati bersama, kecuali tentang gambaran sebuah teori dan ide yang luas bagaimana logika kluster. Beberapa para ahli berpendapat situasi ini bias mengarah kepada kebijakan yang kurang menguntungkan: "terutama bagi pemerintah yang ingin terburu buru mengimplementasikan tentang konsep pendekatan kluster, Beberapa masalah fundamental tentang kluster tengah dihadapi termasuk tentang metode riset yang tepat dan bahkan tentang definisi dari kluster itu sendiri”.

Phenomena tentang perbedaan konsep kluster dari beberapa para ahli, beberapa diantaranya dikemukakan oleh Porter (1998, p.78) yang mendefinisikan kluster sebagai konsentrasi kelompok perusahaan dan berbagai macam institusi yang saling terhubung dalam suatu industry tertentu. Sementara itu DTI (1998, p.22) mendfinisikan kluster sebagai "konsentrasi persaingan, kolaborasi antar perusahaan dan institusi yang saling tergantung dan terhubung oleh system pasar dan non-pasar. Lebih jauh Scottish Enterprise (SE) mendefinisikan kluster sebagai "kelompok konsumen, supplier, competitor dan institusi pendukung lainnya seperti universitas, akademi, badan riset, berbagai institusi keuangan dll (Scottish Enterprise, 1998)

Dalam prakteknya, kluster diartikan sebagai sekelompok perusahaan dan sekelompok institusi bukan bisnis dimana keanggotaan institusi tersebut merupakan elemen penting bagi daya saing individu setiap perusahaan. Menyatukan konsep kluster secara bersama adalah tentang "hubungan antara pembeli dan supplier, atau tentang teknologi yang sering digunakan, pembeli atau saluran distribusi, atau tentang penyediaan lapangan kerja (Enright 1997, p.191). Hal penting untuk dicatat bahwa kluster melibatkan spatial proximity pada tingkat tertentu antara actor actor yang terlibat didalamnya. Geographical proximity mampu membuat hubungan face-to-face, menghasilkan pasar tenaga kerja, dan sebaran ilmu pengetahuan dan skill, terutama "tacit" knowledge yang cukup sulit di kodifikasi.

Di Negara Negara berkembang, network yang kuat jarang ditemukan (Nadvi dan Schmitz, 1994), meskipun internal dan external network sangat penting untuk penyebaran teknologi pada kluster industry (Sandee, 1995: Sandee dan Ter wingel, 2002). Kluster kluster di Indonesia juga dapat digolongkan sebagai kluster dengan network yang lemah (Sato 2000, Supratikno 2001, 2002; Sandee et al 2002; Weijland 1992). Bahkan tambunan (2007) menekankan bahwa hampir semua intervensi pemerintah untuk mendukung pengembangan UMKM telah dilakukan sering kali di Indonesia. Intervensi pemerintah tersebut meliputi subsidi kredit, pengembangan microbank di daerah terpencil, training dan pengembangan sumber daya manusia, Management Quality System ISO-9000yang menyediakan pendampingan quality control, teknologi dan akses internet.

Hampir semua ahli kluster mengakui study tentang kluster berdasarkan pendekatan kluster oleh Michael Porter merupakan titik awal terhadap sebagian besar kajian atau study tentang kluster dan diwaktu bersamaan berusaha memberikan pemikiran dan pemahaman yang lebih luas tentang konsep dan ide kluster industry, dinamika pertumbuhan, perubahan dan keuntungan dalam menggunakan kluster sebagai dasar kebijakan regional (Bergman dan feser, 1999). Pemikiran terkini tentang kluster diinisiasi oleh Michael Enright yang mengusulkan bahwa kajian atau study tentang kluster berdasarkan kajian Michael Porter menjadi titik awal pengembangan kluster dan bukan merupakan sebuah panduan manual yang harus diikuti secara rigid. Dari perspective kebijakan, kluster kluster yang berbeda seringkali sangat spesifik dan kebijakan public tentang kluster haruslah flexible untuk mengakomodasi berbagai industry, institutional dan kondisi politik. 


\section{Kluster Industri Kreatif Dalam Perspective Regional}

Pentingnya industry creative dapat menjadi mesin pertumbuhan ekonomi yang selalu diasosiasikan dengan kualitas sumber daya manusia yang digunakan untuk pengembangan perilaku dan kemampuan individu. Schultz (1961), Becker (1964) dan Barro (1991) adalah yang pertama kali menekankan pentingnya sumber daya manusia dalam menjelaskan pertumbuhan ekonomi. (Jacobs, P.147) menjelaskan bahwa keberagaman human capital akan membawa keberagaman creative outcome di kawasan dimana "setiap orang sangat dekat satu sama lain, dan diantara mereka terdapat perbedaan keahlian, kebutuhan, taste dan supplies.

Terdapat beberapa kajian telah berusaha melihat turunan dan akibat akibat dari adanya ide ide baru dan kemampuan kemampuan dari perspective regional. Beberapa diantaranya, Florida (2002) menyarankan bahwa para peneliti kajian ini harus menekankan pada indicator baru sumber daya manusia, berdasarkan pekerjaan pekerjaan tertentu yang membentuk "creative class", termasuk ilmu pengetahuan alam, teknik, seni, budaya dan hiburan. Lucas (2008) juga memfokuskan pada jalur jalur dimana ide ide baru dapat menghasilkan pertumbuhan yang berkelanjutan, menekankan peran orang orang yang berpendidikan menghabiskan karir mereka dalam bertukar pikiran dan menghasilkan ide ide baru, menyelesaikan pekerjaan mereka terkait dengan masalah yang ada dan menghasilkan pengetahuan yang baru. Lebih jauh Howkins (2002): Barry dan Glaeser (2005) menunjukan terdapat perbedaan sumber daya manusia dari daerah yang berbeda memiliki kecendrungan tumbuh dan berkembang, oleh karena itu menghasilkan kekayaan dan kesejahteraan yang bervariasi antar daerah yang dapat tumbuh antar berbagai daerah dalam suatu Negara tertentu. Saxenian (1994) menekankan pentingnya universitas universitas, para pengusaha, dan terciptanya network yang terkait dalam system industry tertentu yang mampu menghasilkan pembelajaran secara kolektif sebagai factor factor yang mendukung perkembangan industry berteknologi tinggi dalam kawasan tertentu. Morrison (2008) mengikuti pendekatan evolusi dalam mengobservasi kawasan industry, sebagai network dari agen yang beragam, konsentrasi ilmu pengetahuan dalam sebuah komunitas membuat beberapa kawasan menjadi lebih dinamis dibandingkan dengan kawasan yang lainnya.

Pengetahuan dalam sebuah kawasan ekonomi secara mudah diakui sebagai pengetahuan bagi setiap anggota dikawasan tersebut. (Arrow 1962; Lucas 2008). Setiap orang dapat memperoleh pengetahuan dari orang orang sekitar mereka, dan konsentrasi orang orang yang memiliki pengetahuan tinggi sangat membantu pertumbuhan ekonomi. Konsisten dengan asumsi ini, dalam beberapa kajian (e.g Florida, Mallender dan Stolarik, 2008) menyebutkan bahwa universitas sering kali berada di kawasan yang sama dengan dengan keberadaan konsentrasi orang orang yang memiliki keahlian yang tinggi dan kelompok kelas kreatif.

\section{Inovasi pada Kluster industry kreatif}

Burns dan Stalker (1971) menitikberatkan pada inovasi organisasi dan manajemen sebagai produk dari proses social yang terjadi dengan organisasi. Drucker (1985, p.67) menggambarkan inovasi sebagai usaha untuk menciptakan tujuan yang focus pada perubahan dalam dunia bisnis ataupun social. Perusahaan dapat memilih berbagai macam bentuk inovasi mulai dari inovasi produk, strategy, proses, dan pasar, yang dilakukan dengan bekerjasama atau sendiri, tergantung pada tingkat resiko dan komitmen yang telah diputuskan. Inovasi merupakan konsep multi dimensi (Neely et al, 2001).Inovasi dapat didefinisikan sebagai ide, karya ataupun objek yang diterima pengakuannya oleh individu atau kelompok lainnya (Roger, 1995:11). Definisi lain 
tentang inovasi adalah setiap ide, karya atau material artifacts yang dianngap baru oleh unit inatitusi yang relevan (Zaltman et al. 1973:10). Wissema (2005) berpendapat bahwa inovasi adalah pengenalan yang sukses terhadap sesuatu hal yang baru, ukuran sukses adalah dapat diterima oleh pasar atau penggunaan lain. Hal ini mengimplikasikan bahwa inovasi adalah sebagian tentang kemampuan teknis atau proses ilmiah. Inovasi juga merupakan proses komersial, menaruh produk baru di pasar. Dalam literature ilmu manajemen, terutama jika terkait tentang inovasi dan pertumbuhan perusahaan, beberapa jenis inovasi telah diidentifikasi yakni produk, service, proses, pasar, logistic dan inovasi organisasi (Neely et al 2001; Johanessene. Al 2002; Avermaete, 2003)

\section{Network dan Organisasi, kompetisi baru}

Istilah network telah banyak digunakan pada organisasi kontemporer. Dari perusahaan multinational raksasa hingga usaha mikro dan kecil, dari perusahaan manufaktur ke perusahaan jasa, dari perusahaan yang tengah tumbuh seperti industry bioteknologi ke industry traditionalsepertihalnya industry mobil, dari kawasan regional seperti Silicon Valley dan kawasan Prato di Italia dan kawasan nasional seperti Jepang dan Korea, dan lebih banyak organisasi yang terlibat digambarkan sebagai sebuah network. Konsep networking telah menjadi tema yang populer pada level analisis individual: Individu diingatkan terhadap pentingnya apa yang disebut dengan "connection" dalam menyelesaikan masalah dan melangkah maju dalam kehidupan dan oleh karena itu penting untuk melakukan tambahan network. Pertumbuhan jumlah networking mampu membantu orang dalam melakukan berbagai macam kontak hubungan dari menemukan partner hidup hingga partner ventura untuk menghargai ketertarikan akan network. Banyak perusahaan yang dibantu oleh para konsultan telah bergabung, dan menawarkan program in-house training yang membantu para pekerja belajar memaknai pentingnya network dan bagaimana membangun dan menggunakannya.

\section{Industri Pariwisata dan Kerajinan di Pulau Bali Industri Pariwisata di Pulau Bali}

Pulau Bali memiiki luas wilayah 5,632 km2 dan setara dengan 0,29\% total luas wilayah kepulauan Republik Indonesia. Industri pariwisata di pulau Bali memberikan kontribusi terbesar dalam perekonomian Pulau Bali.Perkembangan jumlah kunjungan tourist internasional dan domestic yang terus meningkat merupakan indicator utama perkembanganindustry pariwisata di Pulau Bali.Dari perspektif nasional Bali merupakan pintu gerbang kegiatan ekonomi Indonesia dari sector pariwisata.Pertumbuhan jumlah kunjungan wisatawan seluruh Indonesia, $40 \%$ disumbangkan dari Pulau Bali pada tahun 2010 (BPS, 2011).Hal ini selaras dengan pengembangan pariwisata Pulau Bali yang masuk dalam Rencana Induk Pengembangan Pariwisata Nasional 2011-2025. Konsep ini memiliki rencana perolehan jumlah kunjungan 20 juta wisatawan pada tahun 2025. Pariwisata Bali juga sangat dipengaruhi oleh kondisi ekonomi, politik dan keamanan terutama sejak terjadinya aksi terror pengeboman menyebabkan kunjungan kedatangan tourist mengalami penurunan dan berfluktuasi cukup signifikan. Pariwisata Bali pada mulanya berusaha mengembangkan wisata atraksi budaya untuk meningkatkan jumlah wisatawan yang datang ke Pulau Bali. Namun saat ini konsep wisata Pulau Bali sudah jauh berkembang dengan menawarkan konsep atraksi wisata interaktif seperti kehidupan desa, wisata konsep alam (eco-tourism), dan wisata konsep pertanian (agro-tourism). Atraksi wisata 
petualangan dan olahraga juga terus berkembang untuk mengakomodasi kunjungan wisatawan yang berusia muda.Wisata berbasis marine tourism juga terus berkembang seperti surfing, diving, snorkeling yang berusaha membidik kaum urban untuk melupakan sejenak penatnya tekanan aktifitas di perkotaan.Atraksi wisata MICE (meeting, conference, exhibition) juga turut berkembang dengan pesat dan berusaha membidik kalangan eksekutif dan komunitas bisnis dalam menggabungkan konsep formal bisnis dan rekreasi.

Bali merupakan destinasi wisata yang unik. Wisata budaya, ritual, kepercayaan, keindahan alam merupakan andalan atraksi wisata pulau Bali, yang dapat ditemukan dengan mudah dalam segala aspek kehidupan pada setiap penjuru desa di Pulau Bali.

\section{Industri Kerajinan di PulauBali}

Hampir semua industry kerajinan skala mikro dan kecil di Pulau Bali merupakan hasil kerajinan tangan para pengrajin dan hanya beberapa perusahaan dengan ukuran skala menengah yang menggunakan bantuan mesin. Kluster industry kerajinan ini dipenuhi oleh para pengrajin yang memperoleh keahlian mereka secara turun-temurun, teman, keluarga atau karena sebuah kondisi yang membuat mereka belajar tentang keahlian sebagai pengrajin yang disebabkan karena tuntutan lingkungan sekitar. Para pengrajin memiliki keahlian yang sangat baik dan dikombinasikan dengan muatan kebijakan local dalam menghasilkan sebuah produk usaha kerajinan, Hampir semua pengrajin menghasilkan produk kerajinan tangan hanya mengandalkan ketrampilan dan kreatifitas namun menghasilkan sebuah karya seni. Oleh karena itu dapat dikatakan hampir semua orang yang memiliki kemampuan sebagai pengrajin mendapatkan penghasilan mereka sebagai pengrajin industry kerajinan. Seorang pengrajin biasanya menurunkan ilmu kerajinannya pada anggota keluarga yang dimiliki dan mereka kemudian bekerja bersama sama untuk mendapatkan hasil kerajinan dengan upah yang sangat kecil dan bahkan tidak dibayar. Hal ini lebih dikarenakan hasil upah mereka digunakan untuk menutupi biaya operasional dan hasil kebutuhan sehari hari. Hampir semua industry mikro, kecil kerajinan merupakan usaha informal yang dimiliki oleh para pengrajin yang bekerja berdasarkan order pesanan dari para pedagang atau pengepul. Mereka menjual harga pada kesepakatan harga local pada pedagang atau pengepul dalam kluster industry di wilayahnya. Selanjutnya pedagang menikmati value added dengan menjual kepada buyer local maupun international melalui berbagai skill pemasaran dan penjualan yang dimiliki. Para pedagang mendapatkan keuntungan yang sangat menjanjikan dari lingkaran transaksi dalam kluster. Hal ini disebabkan pendidikan dan skill para pengrajin yang rendah sehingga mereka tidak mampu mengakses pasar industry kerajinan sehingga pedagang dan pengepul menikmati keuntungan signifikan dalam penjualan industry kerajinan dalam kluster ini. Namun terdapat beberapa pengrajin memiliki kemampuan yang sama dengan pedagang dan pengepul dalam mengakses pasar. Hal ini merupakan keuntungan sendiri bagi para pengrajin tersebut. Kemampuan berbahasa, bernegosiasi, pendanaan yang cukup, jalur distribusi, kemampuan menciptakan network dan jiwa wirausaha yang kuat merupakan kunci keberhasilan para pengrajin bertahan dan sukses dalam kluster industry.

\section{Kluster Industri Kerajinan di Pulau Bali}

Keterkaitan antara industry pariwisata dan industry kerajinan di Pulau Bali dapat terlihat dari sebaran konsentrasi kluster industry kerajinan yang saling mendukungdengan zona pengembangan pariwisata di Pulau Bali seperti terlihat pada 
figure 1. Atraksi budaya, ritual dan kepercayaan di Pulau Bali dapat terlihat dari design produk kerajinan yang merepresentasi nilai nilai budaya Pulau Bali dan icon Pulau Bali.

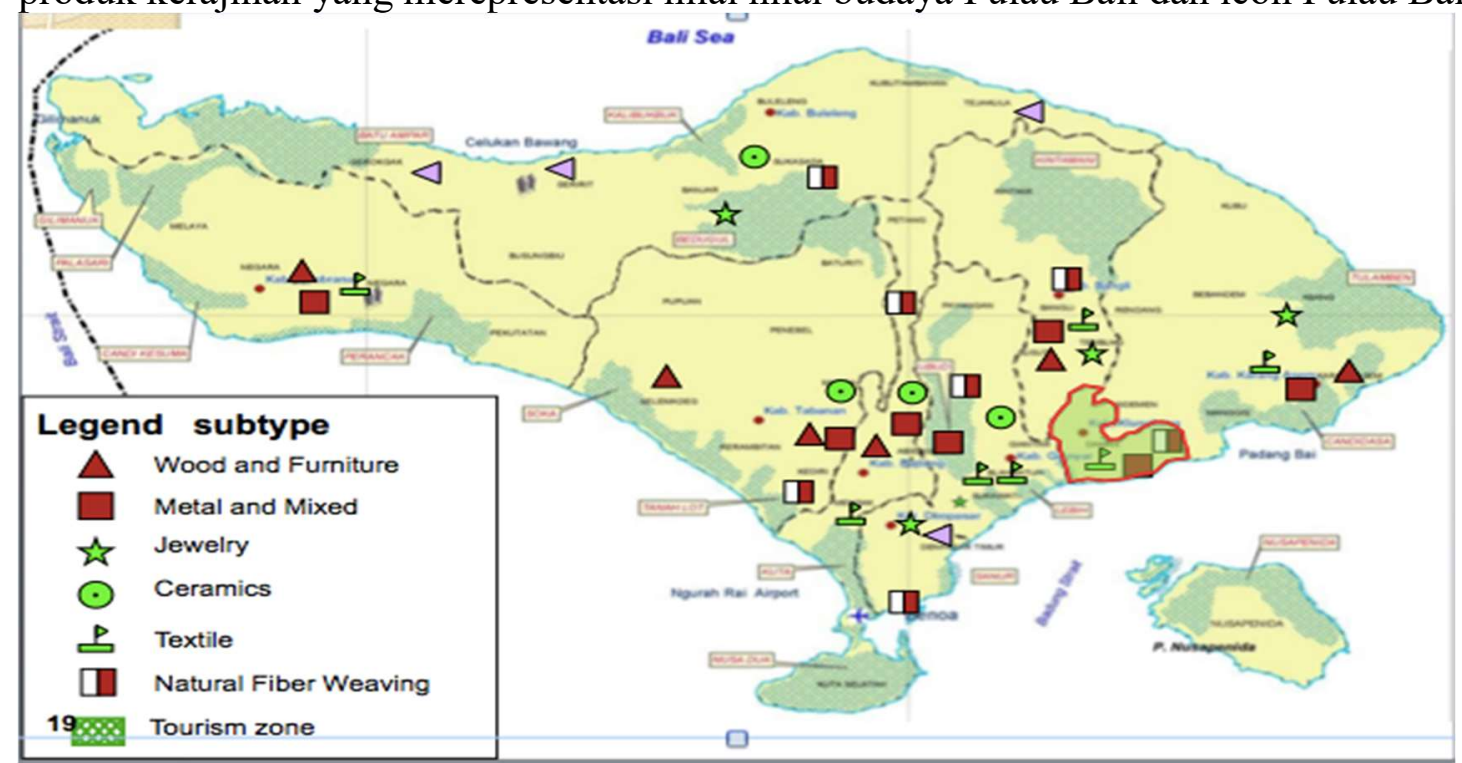

Gambar 1. Kluster industri kerajinan Pulau Bali

Perkembangan industry kerajinan di Pulau Bali sebagai salah satu sector manufaktur menunjukkan kinerja yang sangat baik. Respon pasar baik dalam negeri maupun luar negeri menunjukkan tren yang terus meningkat.Figure 2 menunjukkan gambaran tujuan pasar kluster industry kerajinan Pulau Bali yang sangat aktif menembus pasar local maupun internasional. Berdasarkan tujuan pasar, Indonesia regional dengan jarak pembeli $100 \mathrm{~km}$ dari lokasi bisnis merupakan pasar yang cukup signifikan (82\%), diikuti oleh Indonesia nasional yang menunjukan pasar yang berada diluar pulau Bali atau pulau lainnya di Indonesia (94\%), tujuan pasar Asia dan Eropa (85\%), dan tujuan pasar lainnya (73\%). Hal ini menunjukkan pasar industry kerajinan Pulau Bali telah menembus pasar local maupun internasional dengan capaian keseluruhan pasar tujuan melebihi angka 50\%. Dengan demikian produk kerajinan Bali telah mendunia yang didukung dengan berbagai aktifitas inovasi produk kerajinan sesuai dengan tuntutan pasar local maupun internasional. 
Grafik 1. Tujuan pasar kluster Industri kerajinan Pulau Bali

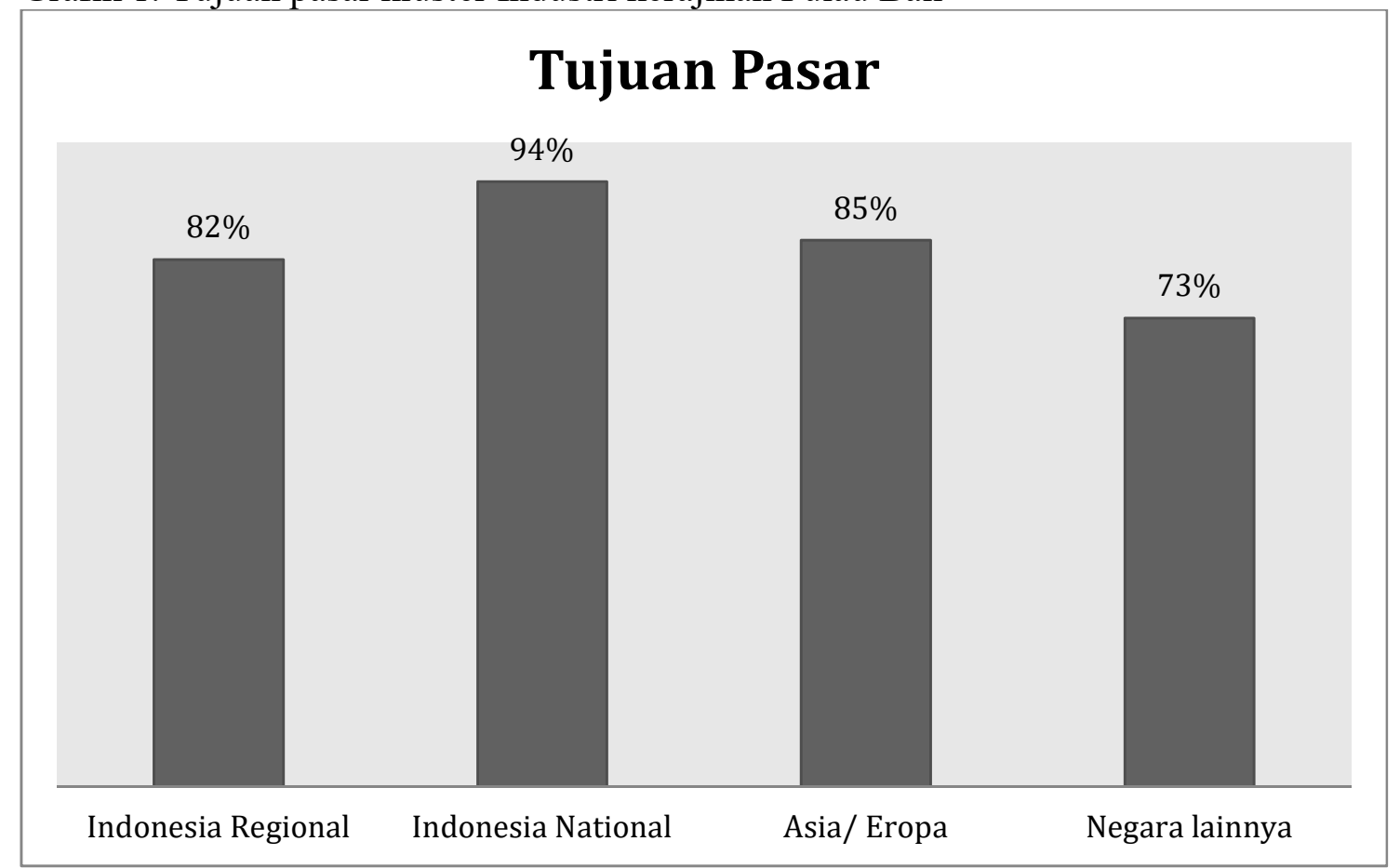

Sumber: Data diolah

Untuk merespon tuntutan pasar yang dinamis dan kompleks berdasarkan letak geografis yang berbeda seperti tergambar dalam Gambar 1, para pengusaha dituntutmampu memahami dan memuaskan kebutuhan konsumen dengan karakter permintaan yang bervariasi berdasarkan karakter preferensi konsumen dari letak geografis yang berbeda. Berbagai aktifitas inovasi dilakukan dalam rangka memenuhi kepuasan konsumen seperti terlihat pada Grafik 2. Hampir semua perusahaan yang menjadi responden dalam penelitian ini melakukan penelitian dan pengembangan terhadap produk kerajinan yang dihasilkan (94\%).Namun hanya beberapa dari mereka melakukan inovasi dengan cara mengakuisisi penelitian dan pengembangan dari luar (3\%). Kegiatan inovasi lainnya seperti melibatkan mesin dalam menghasilkan produk kerajinan demi efektifitas dan efisiensi mencapai angka (58\%), hardware computer (67\%), software computer $(61 \%)$. Aktifitas inovasi dalam mengakuisisi produk perusahaan lain menyentuh angka (52\%) dari total responden, training kegiatan inovasi (27\%), mampu melakukan semua bentuk design produk dalam industry kerajinan (91\%).Lebih jauh lagi hasil penelitian ini menunjukkan semua perusahaan yang menjadi responden dalam penelitian ini melakukan perubahan terhadap design produk $(100 \%)$, dan di sisi lain penelitian pasar mencapai angka (64\%), perubahan metode pemasaran $(27 \%)$, dan meluncurkan periklanan $(27 \%)$ 


\section{Grafik 2. Aktifitas Inovasi Kluster Industri Kerajinan}

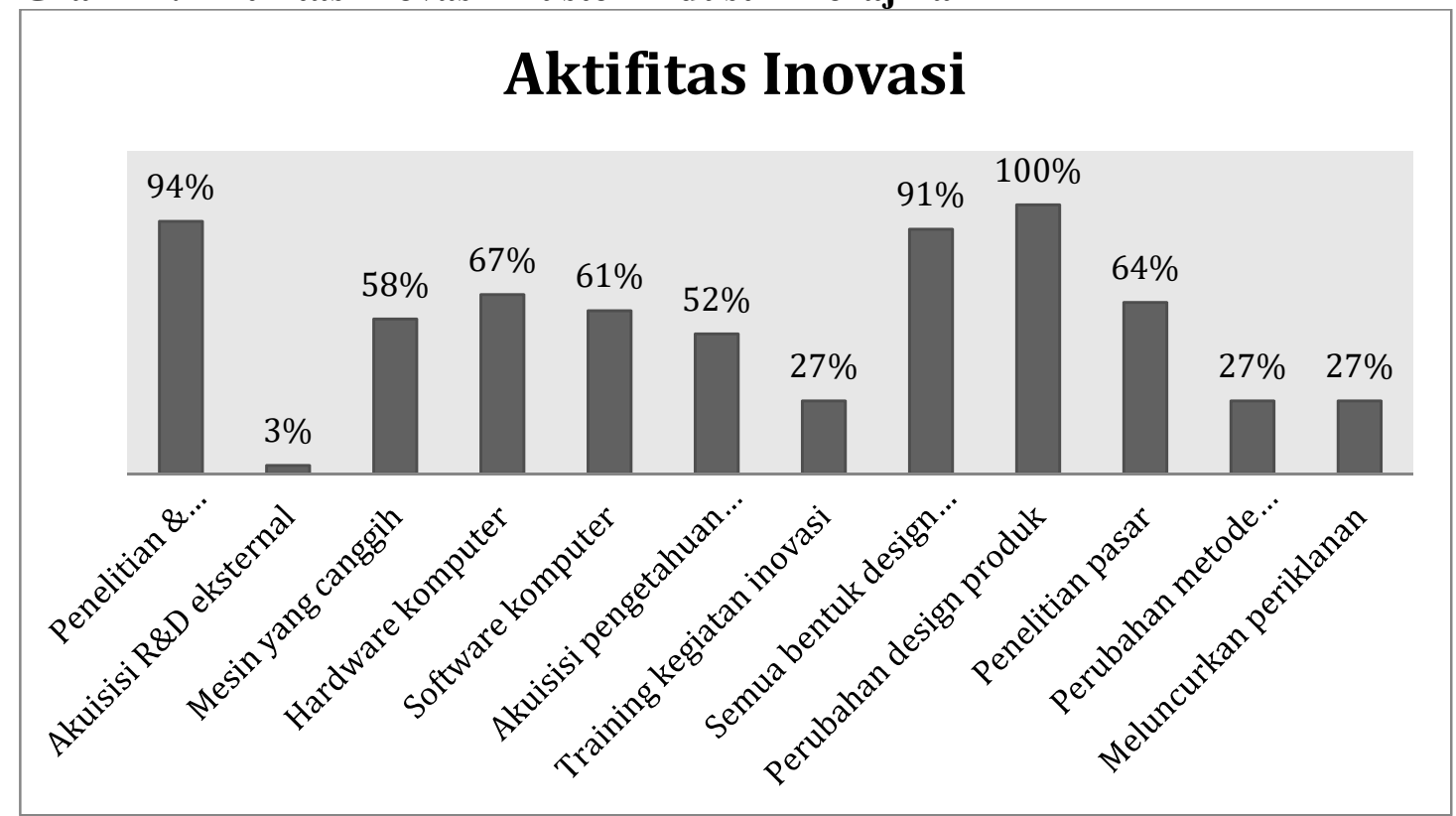

Sumber: Data diolah

Aktifitas inovasi seperti tergambar dalam figure 3 diatas diperoleh melalui berbagai kerjasama dengan berbagai macam institusi baik institusi didalam kawasan yakni Pulau Bali ataupun institusi diluar kawasan yakni Pulau Jawa dan pulau lain disekitarnya dan bahkan institusi yang berasal dari luar negeri. Transfer pengetahuan dan teknologi dari berbagai macam institusi terkait. Dari 33 responden yang menjadi sampel dalam penelitian ini, responden tidak melakukan kerjasama dengan unit bisnis lain dalam perusahaan. Hal ini ditunjukkan dengan nilai rata-rata skor (3.29).Namun sebagian besar responden melakukan kerjasama dengan supplier perlengkapan, material dan jasa untuk mendukung aktifitas inovasi yang dilakukan perusahaan dalam kluster industry kerajinan.Hal ini terlihat dari rata rata persepsi responden mencapai rata rata skor (1.23). Konsumen merupakan sumber agen inovasi usaha kerajinan dalam kluster industry, ditunjukkan dengan skor rata-rata sempurrna (1), Hal ini berarti semua responden yang digunakan dalam penelitian ini mengakui aktifitas inovasi yang mereka lakukan bersumber dari keinginan konsumen. Lebih jauh lagi, pesaing dalam industry juga merupakan sumber atau penyebab pengusaha melakukan aktifitas inovasi dengan capaian rata rata skor (1.87).

Tabel 1. Kerjasama Inovasi dalam kluster industry kerajinan Pulau Bali

\begin{tabular}{|c|c|c|c|}
\hline Partner kerjasama & Minimum & Maximum & Mean \\
\hline Unit bisnis lain dalam perusahaan anda & 1 & 4 & 3.29 \\
\hline Supplier perlengkapan, material dan jasa & 1 & 4 & 1.23 \\
\hline Konsumen & 1 & 4 & 1 \\
\hline Pesaing dalam industry & 1 & 4 & 1.87 \\
\hline Konsultan, lab komersial, R\&D swasta & 1 & 4 & 3.1 \\
\hline Universitas atau perguruan tinggi lainnya & 1 & 4 & 3.26 \\
\hline Pemerintah dan institusi penelitian public & 1 & 4 & 1.58 \\
\hline (Sumber: Data diolah) & Medium & 3. Low & 4. NA \\
\hline
\end{tabular}


Jasa konsultan, lab, komersial, R\&D swasta tidak dimanfaatkan secara signifikan untuk melakukan aktifitas inovasi. Hal ini dapat dilihat dari skor rata rata (3.1), yang berarti kerjasama inovasi melalui jasa konsultan, lab, komersial, R\&D tidak dimanfaatkan oleh sebagian besar responden dalam penelitian ini.Hal serupa diikuti oleh universitas dan perguruan tinggi lainnya dengan capaian rata rata skor (3.26).Hal ini berarti hampir semua responden dalam penelitian ini tidak memanfaatkan universitas dan perguruan tinggi lainnya sebagai sumber kerjasama dalam melakukan berbagai aktifitas inovasi yang tergambarkan dalam figure diatas.Sedangkan pemerintah maupun institusi public memainkan peran yang cukup signifikan dalam mendukung aktifitas pengusaha kerajinan dalam kluster industry kerajinan pulau Bali.

Berbagai hasil kerjasama dengan berbagai macam institusi baik didalam maupun luar kawasan Pulau Bali telah mampu menyebabkan peningkatan pengetahuan dan teknologi.Akumulasi dari pengetahuan dan teknologi mampu mendukung berbagai kegiatan inovasi di kluster industry pariwisata pulau Bali seperti yang tergambar didalam grafik 2.Berbagai kegiatan inovasi tersebut kemudian menjadi hak intelektual property (IPR) kluster industry kerajinan Pulau Bali.Namun berdasarkan responden dalam penelitian ini, hak kekayaan intelektual masih belum disadari dan fahami makna dan fungsinya.Oleh karena itu hanya beberapa anggota kluster industry yang memanfaatkan pengetahuan mengenai hak kekayaan intelektual sebagai asset dan strategi dalam memenangkan persaingan. Hal ini dibuktikan hanya 3\% responden mendaftar patent, $3 \%$ telah mendaftarkan design industry, $6 \%$ anggota telah mendaftar trade mark (merk dagang), dan 6\% telah menghasilkan material untuk untuk copy right. Hak kekayaan intelektual property dimaksudkan untuk melindungi kegiatan inovasi yang telah dilakukan sehingga perusahaan lain tidak dapat mengambil hak kekayaan intelektual sesuka hati mereka namun hendaknya dengan meminta ijin pemilik hak kekayaan intelektual yang dimiliki kluster industry kerajinan.

Grafik 3. Intelektual Property Right (Hak kekayaan intelektual)

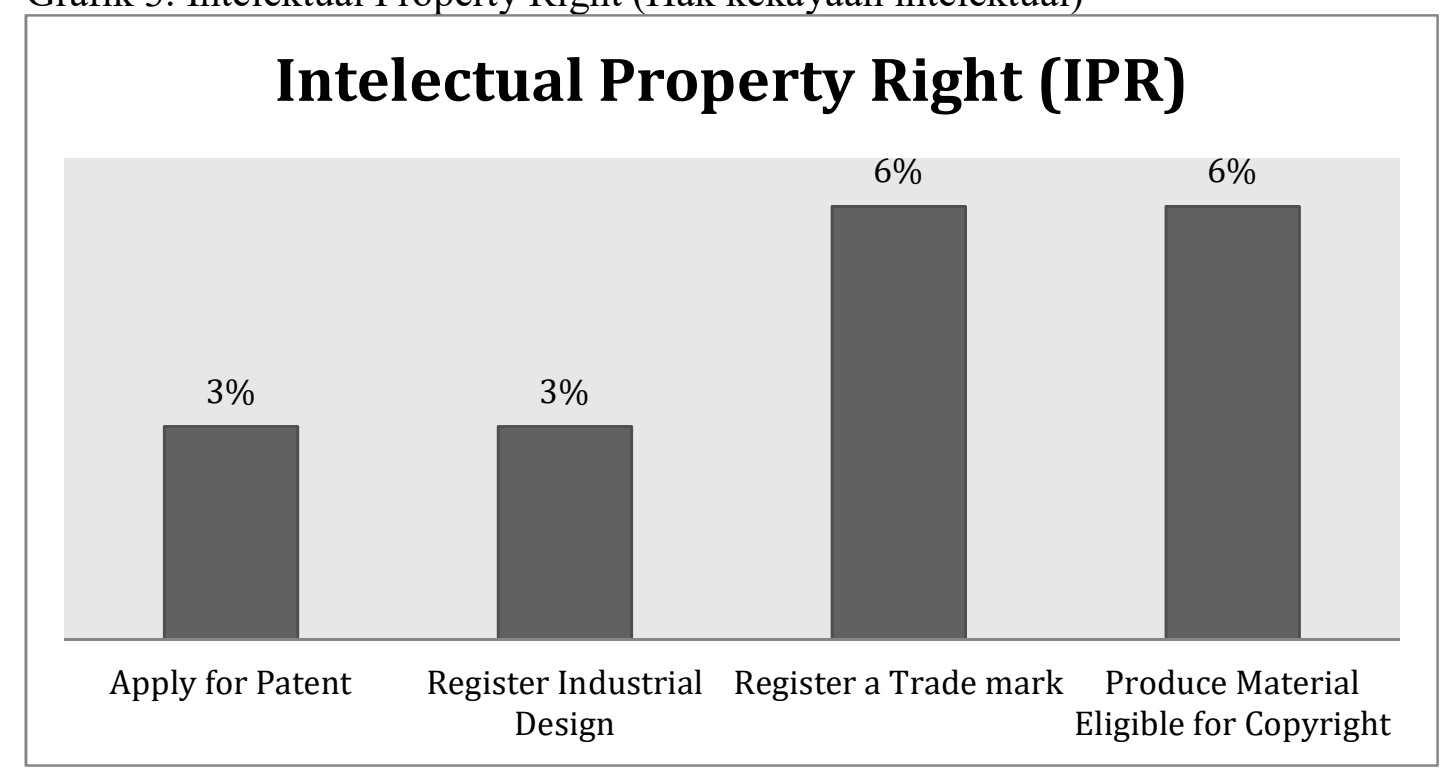

Sumber: data diolah

Secara keseluruhan inovasi dalam penelitian ini dapat ditemukan dalam keunikan kombinasi hubungan baru antara berbagai macam institusi dalam kluster industry 
kerajinan Pulau Bali. Secara garis besar sumber inovasi dapat dilihat dalam 3 aspek yakni inovasi dari sisi penawaran, permintaan dan dari dalam industry kerajinan itu sendiri. Dari sisi penawaran dapat terlihat inovasi yang terjadi karena adanya transfer ilmu dan pengetahuan dari berbagai industry di kawasan kluster industry kerajinan Pulau Bali. Peran berbagai macam asosiasi dalam industry kerajinan seperti Dekranasda, ASEPHI dan asosiasi lainnya sangat membantu perkembangan kluster industry kerajinan. Peran pemerintah daerah, pemerintah pusat, berbagai NGO dan institusi asing lainnya, perusahaan BUMN melalui program CSR, universitas dan perguruan tinggi lainnya memberi dukungan dalam pengembangan inovasi. Dari sisi permintaan, inovasi di dorong oleh permintaan industry pariwisata secara keseluruhan baik secara langsung maupun tidak langsung. Perkembangan industry pariwisata dan teknologi mendorong preferensi konsumen dalam memilih produk industry kerajinan dengan berbagai tujuan. Tujuan bisnis dan pribadi mendominasi preferensi konsumen sehingga mendorong kegiatan inovasi para produsen industry kerajinan. Dari aspek industry kerajinan itu sendiri, aktifitas inovasi dilakukan berdasarkan pengamatan pasar sehingga melakukan berbagai penelitian dan pengembangan produk. Inovasi juga didorong oleh adanya pesaing dalam industry, supplier dalam industry. Dengan adanya pesaing, berbagai perusahaan berlomba untuk membuat design dan proses produk menjadi lebih baik dibandingkan para pesaingnya. Namun dalam persaingan dapat ditemukan juga berbagai kerjasama yang dilakukan. Dalam kluster industry kerajinan dapat ditemukan adanya sharing transaction, infra structure, dan technology. Semua proses aktifitas inovasi tersebut dapat dilihat pada fig. 2 berikut ini:

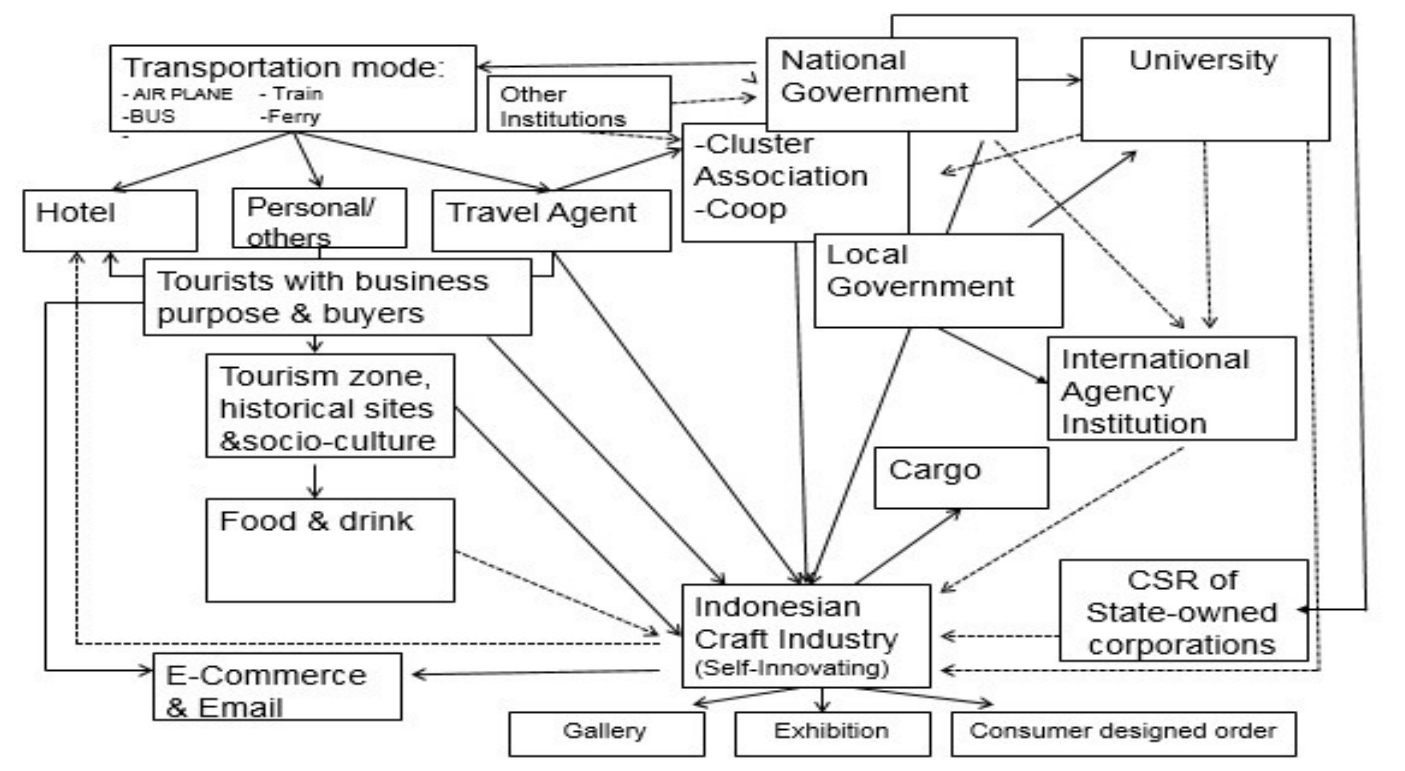

Gambar 2. Kluster industri kerajinan Pulau Bali

\section{KESIMPULAN}

Aktifitas inovasi dalam kluster industry kerajinan dapat dilihat pada hasil olah data yang telah disajikan. Perubahan design produk dan melakukan penelitian \& pengembangan merupakan aktifitas inovasi yang paling kuat dalam kluster industry kerajinan. Namun sebaliknya akuisisi institusi penelitian dan pengembangan perusahaan lain merupakan inovasi yang paling jarang dilakukan oleh anggota kluster yang menjadi responden dalam penelitian ini. Aktifitas inovasi tersebut diatas tercipta dari penciptaan hubungan 
baru yang kompleks antara pemerintah-universitas-industri dalam kluster industry kerajinan Pulau Bali.

Peran universitas dan perguruan tinggi lainnya yang merupakan sumber ilmu pengetahuan dan teknologi berperan sangat tidak signifikan. Meningkatkan peran universitas melalui misi perguruan tinggi yakni: pendidikan, penelitian dan pengabdian secara lebih efektif dan efisien dari berbagai aspek kebutuhan pengusaha kerajinan sangat dibutuhkan.

\section{DAFTAR PUSTAKA}

Arrow, K. J.; "The Economic Implications of Learning by Doing," Review of Economic Studies, vol.29, pp. 155-173, 1962.

Avermaete, T., Viaene, J., Morgan, E.J. and Crawford, N: "Determinants of innovation in small food firms", European Journal of Innovation Management, vol.6 (1), pp. 8-17, 2003.

Barro, R. J.; "Economic Growth in a Cross Section of Countries," Quarterly Journal of Economics, vol.106, pp. 407-443, 1991.

Barry, C.R. and E.L. Glaeser, "The Divergence of Human Capital Level across Cities," NBER, working paper no. 11617, 2005.

Becker, G.; Human Capital: A Theoretical and Empirical Analysis, with Special Reference to Education., New York: Columbia University Press for NBER, 1964.

Bergman, E. and Feser, E. Industrial and Regional Cluster: Concept and Comparative Applications, Regional Research Institute, West Virginia University, 1999.

Best, Michael.: The New Competition. Cambridge, MA: Harvard University Press, 1990.

Burn, T. \& Stalker.; The management of innovation, London, England: Tavistock, 1971.

Department for Culture, Media, and Sport (DCMS); Creative Industries Mapping Document. London, England: Author, 1998.

Drucker, P.F.; "The Dicipline of innovation," Harvard Business Review, vol. 63(3), pp. 67-72, 1985.

DTI; Building the Knowledge Driven Economy.Department of Trade and Industry, HMSO, London, 1998.

Enright, M.; "The Globalization of Competition and the Localization of Competitive Advantage: Policies toward Regional Clustering," in. Globalization of 
Multinational Enterprise and Economic Development, Hood, N. and Young S Macmillan, Ed. London,2000.

Feser, E.; "Old and New Theories of Industry Clusters," in Clusters and Regional Specialisation, Steiner, M. Pion Limited, Ed. London (1998).

Florida, R.; The rise of the creative class. New York: Basic Books, 2002.

Florida, R., Mellander and K. Stolarick.; "Inside the Black Box of Regional Development- Human Capital, the Creative Class and Tolerance," Journal of Economic Geography, vol.8, pp. 615-649, 2008.

German Comission for UNESCO; Training strategies for world heritage management. Bonn, Germany: Author, 2007.

Handke, C.; "On peculiarities of innovation in cultural industries," Paper presented at $15^{\text {th }}$ International conference on cultural economics, Northeastern University, Boston, MA, 2008.

Held, J.; "Clusters as an Economic Development Tool: Beyond the pitfalls," Economic Development Quarterly, Vol. 10, pp. 249-261, 1996.

Howkins, J.; The creative economy.; How people make money from ideas. London: Penguin Books, 2001.

Jacob, J.; The Death and Life of Great American Cities. New York: Random House, 1992.

Kuster, L., \& Vila, N.; "The Market orientation-Innovation-Success relationship: "The role of internationalization strategy," Innovation: Management, Policy \& Practice, vol.13 (1), pp. 36-54, 2011.

Johannessen, J.A., Dolva J.O. and Kolvereid, L.; "Perceive Innovation Success in the Russian Market," International Journal of Information Management vol.17(1), pp.13-20, 1997.

Lucas, R, “Ideas and growth,” NBER, working paper series no 14133, 2008.

Mellander C. and R. Florida, "The Creative Class or Human Capital? Explaining Regional Development in Sweden," CESIS, Working Paper Series No. 79, 2007.

Miles,I., \& Green, L.; Hidden innovation in the creative industries. London, England: NESTA, 2008.

Morrison, A.; "Gate Keeper of Knowledge within Industrial District: Who They Are, How They Interact," Regional Studies, vol.42: pp.817-835, 2008.

Neely, A., Filippini, R., Forza,C., Vinelli,A. and Hii,J.A.: "Framework for analysing business performance, firm innovation and related contextual factor; Perception 
of managers and policy makers in two European regions," Integrated manufacturing Systems, vol. 12(2), pp.114-124, 2001.

Nohria, N, "Is a Network Perspective a Useful Way of Studying Organizations?," Working paper, Harvard Business School, 1992.

Porter, M.E.; On Competition. Harvard Business Review, Harvard School Press, Pp197287, 1998.

Rogers, E.M. Diffusion of innovation. New York; The free press (1998).

Scottish Enterprise; The Cluster Approach: Powering the Scotland's Economy into the $21^{\text {st }}$ Century. Scottish Enterprise, Glasgow, 1998.

Saxenian, AnnaLee.; "Regional Networks and the Resurgence of Silicon Valley," California Management Review, vol.33(1), pp. 89-112, 1990.

Schultz, T. W.; "Investment in Human Capital," American Economic Review, vol.51, pp. 1-17, 1961.

Stoneman, P.; An Introduction to the definition and measurement of soft innovation. London, England: NESTA, 2007.

Tambunan, T.; "Promoting small and medium enterprises with clustering approach: A policy experiences from Indonesia," Journal of Small Business Management, vol. 43(2), pp. 138-154, 2005.

Wright, T., Boria, E.,\& Breidenbach, P. Creative player action in FPS onlinevideo games- playing counter-strike. Game studies. Retrieved 2014 http://www.gamestudies.org/0202/wright

Zackariasson, P., Walfisz, M, \& Wilson, T.L Management of creativity in video game development: A case study. Services marketing quarterly, vol.27, pp.73-97, 2006. 